\title{
Proceedings of the 15th International Symposium on Chromaffin Cell Biology: The Chromaffin Cell as a Stress Transducer
}

\author{
Arturo Hernández-Cruz • Lee E. Eiden
}

Received: 15 October 2010/Accepted: 19 October 2010/Published online: 18 November 2010

(C) Springer Science+Business Media, LLC 2010

It is a great pleasure to present to a larger audience of neurobiologists the Proceedings of the 15th International Symposium on Chromaffin Cell Biology as a Special Issue of Cellular and Molecular Neurobiology. First, a word about the goals of the International Symposia on Chromaffin Cell Biology (ISCCB), and the meeting of which this volume represents the proceedings, and then a brief comment about the organization of this volume itself.

The goal of the ISCCB is to provide a forum for the discussion of original high quality research in neuroscience using mainly, but not exclusively, chromaffin cells as a biological model. The meeting also provides an opportunity to exchange ideas, promote collaboration between laboratories with complementary methodologies, foster scientific strategies, and especially to bring together senior and junior neuroscientists for a protracted period of time making 'non-hierarchical' scientific conversation leading to new ideas and challenging of old ones possible and even inevitable.

The 15th edition of the ISCCB was held in the Hyatt Regency Hotel in Mérida city, Yucatán, México, 12-16th, Nov 2009. The event was announced widely through the Symposium web page (http://www.chromaffincell.org/ merida.html), at the Annual Meetings of the Mexican

\footnotetext{
A. Hernández-Cruz ( $\square)$

División de Neurociencias, Departamento de Neurociencia Cognitiva, Instituto de Fisiología Celular, Universidad Nacional Autónoma de México, Ciudad Universitaria, 04510 México, DF, México

e-mail: ahernan@ifc.unam.mx

\section{E. Eiden}

National Institutes of Health Section on Molecular Neuroscience, Building 49, Room 5A-38, 9000 Rockville Pike, Bethesda, MD 20892-4090, USA
}

Physiological Society and the Society for Neuroscience. It was also announced at the IBRO, IUBMB and ISN web pages.

The participation of young scientists has always been a priority of these Symposia. Thus, for the 2009 meeting, funds were allocated to cover registration and lodging expenses of 27 young scientists. Partial travel aid was provided for four of them. Funds granted by the IUBMB, IBRO, ISN and the National University of México (UNAM) to support this Symposium were used largely to defray the costs of housing and meals of young participants. The total attendance of the 15th ISCCBs was 115 scientists from 22 countries from Europe, Asia, North and South America. More than 40 participants were young scientists. The names of the participants can be found at the ISCCB website (http://www.chromaffincell.org/merida.html) where pdf's of published research and reviews and announcements of future meetings and chromaffin cell-related information is also available.

For the first time, the ISCCB took place in México. This provided the opportunity for researchers from North America, as well as Central and South America to participate to the Symposium and meet well established neuroscientists from all over the world to exchange ideas and perspectives.

An unprecedented number of talks (63 talks in 14 scientific sessions, four plenary lectures, two workshops and one inaugural lecture) were offered throughout the Symposium. In addition, 44 posters were on display during the meeting and time was set aside for their discussion in poster viewing sessions. After the meeting was over, the organizer and members of the Advisory Board were contacted by a number of participants who indicated that the 15th ISCCB represented a highlight in our field and that progress in Chromaffin Cell Biology reported at the 
meeting was of sufficient interest and impact to justify sharing the proceedings of the meeting with a wider neurobiological and neuroendocrine audience. For this purpose, Lee Eiden, on behalf of the ISCCB Advisory Board, contacted the editor of Cellular and Molecular Neurobiology, Dr. Juan Saavedra, who graciously proposed that a Special Issue of the Journal could be dedicated to the Proceedings. Lee Eiden and Arturo Hernández-Cruz, organizer of the 15th ISCCB, then accepted the responsibility for actualizing this project.

Participation in preparing manuscripts of the meeting's proceedings was rapid and comprehensive. This volume represents Original Research Contributions (presentation of original results in standard journal format with Materials and Methods, Results and Discussion, of which there are ten), Reviews (comprehensive review of the subject informed by the perspective of the individual participant, of which there are 14), and Meeting Proceedings (in review format, but including the collective contributions, both published and in preparation, of the presenting laboratory and its collaborators on a specific research focus, just as occurred at the meeting itself, of which there are 17). The formats of these contributions represent more than anything else the cyclic nature of research in this as in any field, with some areas ripe for summary and review, and others representing new avenues in which further investigation is anticipated.

The Special Issue is divided into five chapters that correspond roughly to the structure of the meeting itself. These are Chromogranins, Ion Channels, Secretion Mechanisms, Stress Response Signaling and Clinical and Developmental Aspects. Each section is preceded by a commentary that attempts to identify some of the themes of chromaffin cell biology that are novel, and represent a unique contribution of chromaffin cell research to wider aspects of neurobiology. The co-editors are grateful to have had the opportunity and the privilege to recapture and share the excitement of the 15th ISCCB with the readership of Cellular and Molecular Neurobiology. 